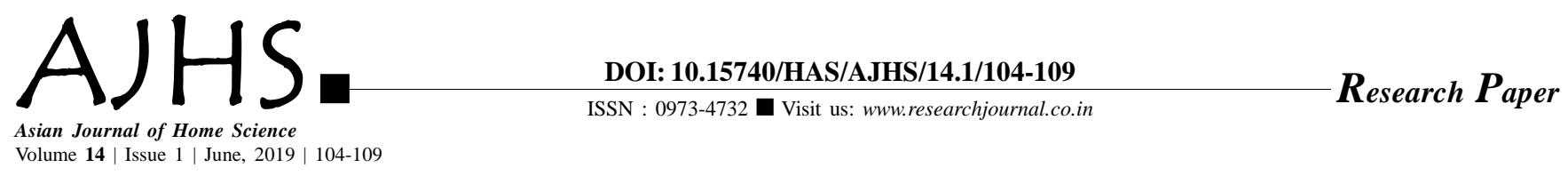

\title{
Mass media and mothers breastfeeding practices
}

\author{
Farzana Alim and Gitanjali
}

Received: 11.01.2019; Revised: 22.04.2019; Accepted: 01.05.2019

See end of the paper for authors' affiliations

\section{Gitanjali}

Department of Home Science,

Aligarh Muslim University,

Aligarh (U.P.) India

Email: gitanjali.designer@gmail

com
ABSTRACT : Every living organism at some specific point of the time want to reproduce themselves, so does the human being. The process of giving care and love to a newborn by various means of activities is known a child-rearing and the activities performed during this are known as child-rearing practices. Feeding is essential for the maintenance of good health and for proper growth and development of babies. Breast milk is ideal for a baby for the first half year of his life.Now a days, with industrialization families are becoming nuclear and there is nobody to guide a mother how to perform her duties for her child. Mass media is an emerging trend which mothers are following in absence or presence of their elders in the home. Mass media is having a large impact on the minds of the audience and is multiplied by them.In the present study, the purpose of this research was to study the impact of mass media on breastfeeding practices. The initial data collection was done with a self-prepared Demographic Questionnaire.CRP Questionnaire is also used and is designed to measure mass media impact on breastfeeding practices. Inferential statistics such as chi-square and correlation are used to see the perceived impact of mass media on breastfeeding practices of mothers. The mass media is having an impact on mother's breastfeeding practices to some extent in urban areas of Aligarh whereas in rural areas no perceived impact is seen as mothers are following practices told by their elders and doctors. Although mothers in both regions i.e. urban and rural areas are practicing best breastfeeding practices.

KEY WORDS: Mass media, Breastfeeding practices, Mothers, Urban, Rural areas

- HOW TO CITE THIS PAPER : Alim, Farzana and Gitanjali (2019). Mass media and mothers breastfeeding practices. Asian J. Home Sci., 14 (1) : 104-109, DOI: 10.15740/HAS/AJHS/14.1/104-109. Copyright@ 2019: Hind Agri-Horticultural Society. 